Alwaely, S. A., \& Jarrah, H. Y. (2020). Occupational burnout and its relation to academic staff performance at Al Ain University, college of education (evaluation study), International Journal of Cognitive Research in Science, Engineering and Education (IJCRSEE), 8(3), 19-28.

Original scientific paper

UDK:

Received: September, 18.2020

Revised: November, 11.2020.

Accepted: November, 17.2020.

doi: 10.23947/2334-8496-2020-8-3-19-28

\title{
Occupational Burnout and its Relation to Academic Staff Performance at Al Ain University, College of Education (Evaluation Study)
}

\author{
Suad Abdelkareem Alwaely ${ }^{1 *}$, Hani Yousef Jarrah ${ }^{1}$
}

1Al Ain University, Abu Dhabi, UAE, e-mail: alwaely_s@yahoo.com; h.jarrah12@yahoo.com

\begin{abstract}
This study aims to identify the occupational burnout and its relation to teaching performance among Al Ain University (AAU) academic staff. The sample of the study consisted of 60 male and female teachers of Al Ain University First Directorate of Education. The researchers designed two tools for the study, represented in occupational burnout questionnaire for teachers and teaching performance questionnaire. The results show that teachers in the education college in AAU have a moderate level of occupational burnout. There are differences in the occupational burnout level for the favor of females, and differences in teaching experience for the favor of 10 years and more. The researchers ascribe this result to increased workloads and stress that female teachers face. Female teachers are more exposed to occupational burnout than male teachers because female teachers also face loads in connection with household and family concerns. There is as well an inverse relationship with statistical differences between occupational burnout level for teachers and their performance level. The study results in many recommendations and suggestions.
\end{abstract}

Keywords: occupational burnout, teachers, teaching performance, teaching experience.

\section{Introduction}

Occupational burnout is a response to the impacts that affect the teacher, such as workload, which increases his/her personal commitments and responsibilities, due to these responsibilities, the teacher may start to feel psychological exhausting, therefore, it might affect his/her performance (Lastovkova et al., 2018).

Occupational burnout is a phenomenon that leads to physical exhaustion, emotional fatigue, and psychological disorders, in addition to a negative effect on teacher's attitude toward his/her job and his/ her educational outcomes. Therefore, studying the occupational burnout comes with positive results for the teacher and the educational process, by avoiding negative impacts, helping the teacher to fulfill his/her needs, to achieve job satisfaction, to remove problems and obstacles that hinder him/her from achieving the required psychic wellness (Torkaman et al., 2017).

Self-exhaustion, depersonalization, and underestimating personal achievements are the dimensions of occupational burnout. The first dimension shows a feeling of loss of power and exhaustion of emotional and psychological resources. In the second dimension, a teacher shows indifference for what others feel and uses inappropriate words. In the third dimension, a teacher tends to negative self-esteem, feels less efficient and demonstrates a decline in performance (Bawakid et al., 2017).

Rehman, S.u. et al., (2017) define occupational burnout as a condition of an individual when he/ she feels that his/her requirements are not fulfilled and his/her expectations are not met, accompanied with disappointment, psychological and physical symptoms that lead to low self-esteem, and burnout evolves gradually with time. Atiyat (2017) define it as a psychological condition that makes individuals feel exhausted and tired, resulting from extra burdens, makes them feel that they are unable to endure these burdens. Such worker's condition might also affect those people who work (or are in close contact) with them.

Alfarra (2004) and Kim, Jörg and Klassen (2019) mention that the educational sector is one of the most vulnerable sectors to occupational burnout due to teacher's workload. Education sector is a cornerstone for society, thus, reducing occupational burnout is necessary for teachers to achieve education quality, otherwise, job perfection and the desired teaching outcome will not be achieved.

Alfarra (2004) defines teaching performance by a method that shows teacher's possession of necessary teaching skills. Davis (2017) defines it by teacher's performance and achievement within the *Corresponding author: alwaely_s@yahoo.com 
available circumstances and capacities regardless of the efforts and time it takes.

Bal-Taştan et al., (2018) sees the necessity to involve teachers in making the decisions related to education, also, to prepare the curricula with teachers' collaboration as long as the achievement evaluation is not separated from teaching methods. It is certainly that school management system and teachers' overall performance will gain more benefits by involving teachers in decision-making process.

The researchers point out that teachers' occupational burnout results from their work environment, which is represented by overloaded curricula when compared with the estimated time schedule to cover it, its inappropriateness for students' capacities, low salaries, increased teaching load, lack of parents' involvement, and other issues. The said should stimulate the principals and supervisors to do their best to reduce the factors that lead to teachers' burnout.

Abu Masoud (2010) aimed to identify the occupational burnout phenomenon for administrative employees working within the Ministry of Education in Gaza Strip. The author studied occupational burnout causes, and how to deal with them. The results showed that employees were generally suffering from a medium level of occupational burnout in two aspects (emotional exhaustion and depersonalization), while the burnout level was low in the aspect of personal achievement.

Besides, Anthony-McMann al., (2017) aimed to identify the impact of stress and occupational burnout on the occupational performance in various workplaces. The results showed that job stress led to occupational burnout and employees became unable to achieve perfect results.

Woodhead, Northrop and Edelstein (2016) aimed to identify the impact of job stress and social support on occupational burnout among long-term care nursing staff. The results showed that job stress was associated with emotional exhaustion, depersonalization, and low-level of achievement, while social support, on the contrary, decreased occupational burnout.

In addition, Altalla' (2015) aimed to identify the occupational burnout and its causes for workers in Gaza Governorate Electricity Distribution Company. The results showed a medium degree of burnout for the employees, a high degree of emotional exhaustion, a moderate degree of depersonalization, but a small number of workers with low-level of achievement.

Harzallah (2018) discussed Palestinian teachers' occupational demands and their performance. The authors assessed current training programs, time allocated for studies, training place, and potentials.

Ward and Ayvazo (2016) discussed a strategy to develop teaching performance for physical education teachers and its impact on teaching outcomes for elementary stage students. Most important results were that the suggested strategy had a positive impact on teaching performance level for physical education teachers.

Besides, some researchers aimed to identify the occupational burnout for teachers in Gaza Strip (Alfarra, 2004) and its relation to their teaching performance level and career compatibility (Kim, Jörg and Klassen, 2019). The results showed that there was no significant relationship between the level of occupational burnout and teaching performance level, and there was a significant negative relationship between the level of burnout and the level of career compatibility.

So far, research on teaching staff burnout does not provide a sufficiently clear answer to what critical factors regarding gender, social differences and experience influence the rate of burnout and, accordingly, the impact on which factors can eliminate this phenomenon. Most studies, as indicated above, arrive at a similar definition of factors, but often disagree in assessing their significance or pre-dominant influence. With regard to research on this topic in the Arabic-speaking region of the Middle East, most of the studies carried out are significantly outdated (up to 10 years or more) and need updating due to significant socio-economic and technological changes in this region. It is the partial elimination of these two gaps in research that is intended to close this research.

\section{Study Problem and Questions}

Teachers might suffer from occupational burnout due to the importance of their mission, tasks, and the role they play. The nature of teacher's job makes him/her vulnerable to depression due to such job stresses as intensive curriculum, crowded classrooms, inability to control some students' behavior, lack of communication between the management and the teacher, in addition to low income. In order to take care of their job, teachers should work on eliminating the obstacles that lead them to lose psychological satisfaction, they are to overcome job stress, reduce occupational burnout, and its negative results (Nuri, Demirok and Direktör, 2017).

Therefore, it is needed to identify the relationship between occupational burnout and teaching performance among teachers at Al Ain University. The study tries to answer the following questions:

(1) What is the level of burnout among teachers at Al Ain University of Science and Technology? 
(2) Are there significant statistical differences $(\alpha<0.05)$ in the level of teachers' burnout that could be ascribed to the variables (gender, scientific qualification, teaching experience)?

(3) Are there significant statistical differences $(\alpha<0.05)$ between the level of teachers' burnout and their teaching performance?

\section{The Importance of the Study}

(1) Theoretical importance: the study provides a profound understanding of the nature of teachers' occupational burnout, its factors, teaching performance, and means to overcome occupational burnout.

(2) Practical importance: the tools and results of the study can be applied while creating a preventive program that diagnoses occupational burnout phenomenon among teachers and finds the proper methods to reduce it.

\section{Material and Methods}

The researchers used the descriptive method, as it was appropriate for the goals and the nature of the study.

\section{Population and sample of the study}

The population of the study consisted of 60 teachers ( 28 female and 32 male) from Al Ain University. The study was conducted during 2018-2019. The researchers followed the random method by distributing 60 questionnaires to the population of the study; therefore, the sample of the study consisted of 60 male and female Arabic language teachers.

Tools of the study:

Occupational Burnout questionnaire: the researchers used a questionnaire to collect data related to the goal of the study; the questionnaire consisted of 30 items in its final version.

Teaching performance questionnaire (consisted of 30 items in its final version).

\section{Tools' Validity and Reliability}

Both questionnaires were presented to a group of specialized and experienced referees. Items were modified and rephrased based on referees' opinions. Then, occupational burnout and teaching performance questionnaires were formed. To verify the reliability of the tools they were applied on a separate sample, exterior to the study sample. This separate sample consisted of 20 male and female teachers. Pearson correlation was calculated and Cronbach's alpha formula was applied to evaluate the reliability of the study tools (see table 1).

Table 1.

Pearson correlation and Cronbach's alpha

\begin{tabular}{lll}
\hline Study tool & Cronbach's alpha & Pearson correlation \\
\hline Occupational burnout questionnaire & 0.88 & 0.77 \\
Teaching performance questionnaire & 0.83 & 0.78 \\
Total & 0.93 & 0.76 \\
\hline
\end{tabular}

* Statistically significant at the level $(a \leq 0.05)$

\section{Procedural definitions}

Occupational burnout: a state of physical exhaustion, emotional exhaustion, which a teacher feels due to severe and continuous job pressures. Occupational burnout was analyzed in this study with the help of questionnaires prepared for this purpose.

Teaching performance: teacher's work toward achieving his/her educational goals during the class or the semester. Teaching performance is measured with the help of questionnaires prepared for this purpose. 


\section{Procedures of the study}

To achieve the goals of the study, the following procedures were done:

(1) Problem statement, identifying the importance of the study and its theoretical framework.

(2) Determining the population and the sample of the study.

(3) Forming the tools of the study, verifying their validity and reliability.

(4) Tools of the study were applied to measure the level of occupational burnout and its relation to teaching performance among teachers in AAU.

(5) Data processing through SPSS and performing statistical analysis.

Statistical analysis:

(1) Tools' reliability evaluation using Pearson method and Cronbach's alpha.

(2) Means and standard deviations for the sample responses.

(3) Three-way ANOVA for demographic variables (gender, qualification, experience).

(4) Scheffe test for post hoc comparisons according to the experience variable.

\section{Limitations of the study}

The study is limited to a sample of Arabic language teachers at Al Ain University for the academic year 2015-2016. Both tools of the study were verified for validity and reliability.

\section{Results} AAU?"

Results related to the first question of the study: "What is the level of burnout among teachers at

To answer this question, means and standard deviations were calculated for the responses of the sample to the questionnaire items related to occupational burnout, as shown in Table 2. 
Alwaely, S. A., \& Jarrah, H. Y. (2020). Occupational burnout and its relation to academic staff performance at Al Ain University, college of education (evaluation study), International Journal of Cognitive Research in Science, Engineering and Education (IJCRSEE), 8(3), 19-28.

Table 2.

Measuring respondents' attitudes towards occupational burnout, descending according to the mean

\begin{tabular}{|c|c|c|c|c|c|}
\hline Rank & Number & Item & Mean & $\begin{array}{l}\text { Standard } \\
\text { Deviation }\end{array}$ & $\begin{array}{l}\text { Evaluation } \\
\text { degree }\end{array}$ \\
\hline 1 & 30 & $\begin{array}{l}\text { I feel it hard to set down and feel } \\
\text { relaxed after one day of teaching }\end{array}$ & 4.71 & 0.58 & Moderate \\
\hline 2 & 15 & $\begin{array}{l}\text { I would leave my job if I found another } \\
\text { one }\end{array}$ & 3.79 & 0.96 & Moderate \\
\hline 3 & 28 & I feel depressed because of my job & 3.65 & 0.85 & Moderate \\
\hline 4 & 10 & $\begin{array}{l}\text { I lose my temper when my students do } \\
\text { not do the tasks I give them }\end{array}$ & 3.59 & 0.81 & Moderate \\
\hline 5 & 14 & I deal quietly with my nervous students & 3.58 & 0.79 & Moderate \\
\hline 6 & 26 & $\begin{array}{l}\text { I feel worried because this job } \\
\text { increases emotional burnout }\end{array}$ & 3.58 & 0.82 & Moderate \\
\hline 7 & 5 & I intentionally go late to work & 3.56 & 0.84 & Moderate \\
\hline 8 & 16 & $\begin{array}{l}\text { I feel content when I do not show up to } \\
\text { work }\end{array}$ & 3.56 & 0.74 & Moderate \\
\hline 9 & 9 & $\begin{array}{l}\text { I feel that my relationship with my } \\
\text { students is negative }\end{array}$ & 3.55 & 0.76 & Moderate \\
\hline 10 & 6 & $\begin{array}{l}\text { I feel continuous exhaustion when I } \\
\text { wake up and I know that I have to face } \\
\text { a new day }\end{array}$ & 3.54 & 0.78 & Moderate \\
\hline 11 & 8 & I feel that I am emotionally exhausted & 3.51 & 0.84 & Moderate \\
\hline 12 & 17 & $\begin{array}{l}\text { I can easily create a soothing } \\
\text { environment with my students }\end{array}$ & 3.51 & 0.74 & Moderate \\
\hline 13 & 4 & $\begin{array}{l}\text { I feel that the students blame me for } \\
\text { the problems they face }\end{array}$ & 3.50 & 0.84 & Moderate \\
\hline 14 & 19 & $\begin{array}{l}\text { I feel that my students' attitudes } \\
\text { increase my job pressures }\end{array}$ & 3.49 & 0.80 & Moderate \\
\hline 15 & 3 & $\begin{array}{l}\text { I deal effectively with my students' } \\
\text { problems }\end{array}$ & 3.48 & 0.74 & Moderate \\
\hline 16 & 13 & $\begin{array}{l}\text { I feel psychological stress for doing this } \\
\text { job }\end{array}$ & 3.48 & 0.76 & Moderate \\
\hline 17 & 25 & $\begin{array}{l}\text { I have done a lot of good things in my } \\
\text { current job }\end{array}$ & 3.44 & 0.73 & Moderate \\
\hline 18 & 27 & $\begin{array}{l}\text { I feel that I have become harsh with } \\
\text { people because of my work as a } \\
\text { teacher }\end{array}$ & 3.43 & 0.81 & Moderate \\
\hline 19 & 12 & $\begin{array}{l}\text { I feel low motivation toward working as } \\
\text { a teacher }\end{array}$ & 3.38 & 0.70 & Moderate \\
\hline 20 & 23 & $\begin{array}{l}\text { The management gives me the } \\
\text { appreciation I deserve }\end{array}$ & 3.34 & 0.71 & Moderate \\
\hline 21 & 1 & $\begin{array}{l}\text { I think that job stress that I face is } \\
\text { because of my physical illness }\end{array}$ & 2.99 & 0.84 & Low \\
\hline 22 & 22 & $\begin{array}{l}\text { I feel that I deal with some students as } \\
\text { objects, not humans }\end{array}$ & 2.63 & 0.66 & Low \\
\hline 23 & 2 & $\begin{array}{l}\text { I find it hard to control my temper due } \\
\text { to my teaching job }\end{array}$ & 2.62 & 0.71 & Low \\
\hline 24 & 24 & $\begin{array}{l}\text { I feel that I have a positive effect on } \\
\text { others }\end{array}$ & 2.61 & 0.70 & Low \\
\hline 25 & 18 & I feel depressed due to my teaching job & 2.54 & 0.67 & Low \\
\hline 26 & 20 & I feel exhausted due to my teaching job & 2.54 & 0.77 & Low \\
\hline 27 & 21 & $\begin{array}{l}\text { I feel that I affect positively others' life } \\
\text { by performing this job }\end{array}$ & 2.52 & 0.74 & Low \\
\hline 28 & 7 & $\begin{array}{l}\text { I feel distress when one of my students } \\
\text { discusses something with me }\end{array}$ & 2.51 & 0.73 & Low \\
\hline 29 & 11 & $\begin{array}{l}\text { I feel happy and content after working } \\
\text { with my students }\end{array}$ & 2.45 & 0.75 & Low \\
\hline 30 & 29 & $\begin{array}{l}\text { I would have worked better as a } \\
\text { teacher if I had not faced too many } \\
\text { problems }\end{array}$ & 2.42 & 0.81 & Low \\
\hline \multicolumn{3}{|c|}{ Occupational burnout as a whole } & 3.25 & 0.25 & Moderate \\
\hline
\end{tabular}


Table 2 shows that means of respondents' ratings of items relating to occupational burnout range from 2.42-4.71. Item 30 ("I feel it hard to set down and feel relaxed after one day of teaching") ranked first with a mean of 4.71 and moderate evaluation degree. Item 29 ("I would have worked better as a teacher if I had not faced too many problems") ranked last with a mean of 2.42 and low evaluation degree. Occupational burnout as a whole scored 3.25 with a moderate evaluation degree. The latter points out that occupational burnout degree among AAU teachers is moderate. The researchers attribute it to the result of multiple workloads that make a teacher vulnerable to occupational burnout. Workers in public sectors in general, especially in teaching sector, suffer from a lack of social support from family, supervisors, and colleagues. Thus, teachers feel psychological insecurity while performing their job, especially when they face difficulties or threats and recognize that they are not capable to face them anymore and that they need assistance.

The study sample does not suffer from high occupational burnout; the researchers ascribe this to low psychological stress in teachers of the study sample. Besides, positive stress contributes to individual's ability to endure and direct attention toward the need, and to reevaluate the situations and avoid conflicts with others. Pressures of this kind may as well add a sort of pleasure to life.

Results related to the second question: "Are there significant statistical differences $(\alpha<0.05)$ in the level of teachers' burnout that could be ascribed to the variables (gender, scientific qualification, teaching experience)?"

To answer this question, means and standard deviations were calculated for the sample responses regarding teachers' burnout in relation to the variables (gender, scientific qualification, teaching experience). Three-way ANOVA analysis was applied, as shown in Table 3.

Table 3.

Means and Standard Deviations for sample responses about occupational burnout in relation to the variables (gender, scientific qualification, teaching experience) $(n=140)$

\begin{tabular}{llcc}
\hline Variable & Level & Mean & $\begin{array}{c}\text { Standard } \\
\text { Deviation }\end{array}$ \\
\hline \multirow{2}{*}{ Gender } & Male & 3.14 & 0.17 \\
& Female & 3.29 & 0.27 \\
Qualification & BA & 3.30 & 0.26 \\
& Assistant, Associate professor & 3.21 & 0.24 \\
Experience & Less than 5 years & 3.18 & 0.20 \\
& 5-10 years & 3.13 & 0.20 \\
\hline
\end{tabular}

Table 3 shows differences among the means of sample responses about level of occupational burnout ascribed to the variable (gender, qualification, experience). To identify the statistical significance of these differences, three-way ANOVA analysis was applied, as shown in table 4.

Table 4.

Results of Three-way ANOVA application

\begin{tabular}{lccccc}
\hline Source & Total squares & $\begin{array}{c}\text { Degree of } \\
\text { freedom }\end{array}$ & $\begin{array}{c}\text { Mean of } \\
\text { squares }\end{array}$ & F & $\begin{array}{c}\text { Statistical } \\
\text { Significance }\end{array}$ \\
\hline Gender & 0.28 & 1 & 0.28 & 5.64 & 0.02 \\
Qualification & 0.001 & 1 & 0.001 & 0.03 & 0.87 \\
Experience & 1.48 & 2 & 0.74 & 14.81 & 0.00 \\
Error & 6.74 & 135 & 0.05 & & \\
Total & 1487.42 & 140 & & & \\
Corrected Total & 8.88 & 139 & & & \\
\hline
\end{tabular}

Tables 3-4 show that:

(1) There are significant statistical differences at the level $(\alpha=0.05)$ in the sample responses about the level of occupational burnout among AAU teachers ascribed to the gender variable. $F$ value is 5.64 , 
which is statistically significant. While the mean of 3.29 in table 3 shows that the differences are in favor of females. The researchers ascribe this result to increased workloads and stress that female teachers face. This result can be justified by saying that female teachers are more exposed to occupational burnout than male teachers are since female teachers, in addition to workloads, also face loads on a personal level such as home routines, child care, etc. This result is contrary to the study of Alnouri (2011), who shows that males are more exposed to burnout than females are.

(2) There are no significant statistical differences at the level $(\alpha=0.05)$ in the sample responses about the level of occupational burnout ascribed to qualification variable. $F$ value is 0.03 , which is not statistically significant. The researchers ascribe this result to the fact that all teachers with different scientific qualifications face similar circumstances and stress, which reduce the differences in the levels of their occupational burnout.

(3) There are no significant statistical differences at the level $(\alpha=0.05)$ in the sample responses about the level of occupational burnout among AAU teachers ascribed to experience variable. $F$ value is 14.81 , which is statistically significant. In order to know the source of these differences, Scheffe test was applied for the post hoc comparisons, as shown in table 5.

Table 5.

Scheffe test results for post hoc comparisons of the levels of occupational burnout according to the variable of experience

\begin{tabular}{ccccc}
\hline Teaching experience & Mean & Less than $\mathbf{5}$ years & $\mathbf{5 - 1 0}$ years & $\mathbf{1 0}$ years and more \\
\hline Less than 5 years & 3.18 & & 0.05 & $-0.22^{\star}$ \\
$5-10$ years & 3.13 & & $-0.27^{\star}$ \\
More than 10 years & 3.40 & & \\
\hline
\end{tabular}

* Statistically significant at the level $(\alpha=0.05)$

Table 5 shows differences between the teaching experience of "less than 5 years" and "more than 10 years" in favor of "more than 10 years" with a mean of 3.40 , while the mean for teaching experience "less than 5 years" is 3.18. The differences between teaching experience " $5-10$ years" and "more than 10 years" are in favor of the experience "more than 10 years". The researchers ascribe this result to the fact that teachers with long experience are more exposed to burnout compared to others. This result agrees with Alnouri (2011), who shows that there is an impact of the age variable on the occupational burnout, i.e., experienced teachers are the ones who suffer from teacher burnout most.

Results related to the third question: "Are there significant statistical differences $(\alpha \leq 0.05)$ between the level of teachers' burnout and their teaching performance?"

In order to answer this question, Pearson correlation coefficient was calculated between the level of occupational burnout among AAU teachers and their teaching performance, as shown inTable 6 .

Table 6.

Pearson correlation coefficient between the level of AAU teachers' occupational burnout and their teaching performance

\begin{tabular}{lll}
\hline Field & & Teaching Performance \\
\hline \multirow{2}{*}{ Occupational burnout } & Correlation coefficient & -0.19 \\
& Statistical significance & 0.03 \\
\hline
\end{tabular}

Table 6 shows that the correlation coefficient value between occupational burnout and teaching performance is -0.19 , which is a negative and statistically significant value at the level $(\alpha<0.05)$, which points out an inverse correlation between the level of occupational burnout among AAU teachers and their teaching performance. This result indicates low teaching performance as a result of high level of occupational burnout, namely, the more frequent and severe psychological burnout, the lower teaching performance level. 


\section{Discussion}

The problem of teacher burnout is closely intertwined with the analysis of their teaching experience and analysis of the sources of stress and stress in teaching. While this study looks at significant burnout factors and groups of educators who are more prone to burnout, other researchers are focusing more on specific causes of burnout and stress (Abu Masoud, 2010; Atiyat, 2017). It should be noted that the results of various studies are in conflict with each other, as, for example, in the case of the study Alnouri (2011), which indicates a greater propensity for burnout of male teachers, while our study received the opposite result. The reason for the discrepancy can be both a systemic discrepancy in the formation of a sample from the general population of teachers, and the difference in the manifestation of a feature depending on the geographic region, ethnic characteristics and other factors that have not yet been sufficiently studied (Bawakid et al., 2017; Altalla', 2015).

Also, a number of studies on gender burnout or work exhaustion show mixed results. In different conditions and in different studies, a higher level of burnout is indicated either in men or in women, moreover, the factors of the bias in the assessment have not yet been thoroughly studied (Abu-Hilal and Kilani, 2018; Yorulmaz and Altinkurt, 2018; Al Serhan, 2020). Our study confidently demonstrates that among faculty members, fatigue prevails among women. There are objective social reasons for this, the traditional way of family in the region under study, in which a woman traditionally bears most of the family and household loads in addition to work (Garcia-Arroyo, Osca Segovia and Peiró, 2019).

The distribution of the factors determining burnout is still poorly studied. Researchers point out that the cause of burnout is stress, attempts to perform more functions, overwork, as well as a lack of adequate social support and correct distribution of labor (Alfarra, 2004; Kim, Jörg and Klasse, 2019; Davis, 2017). It is pointed out that these factors equally affect the majority of teachers, which is in line with the results of our study indicating that skill level does not affect burnout in any way. It remains an open question as to whether burnout can be stopped without drastic changes in educational management practices or changes in the social composition of teachers (Abu Masoud, 2010).

The researchers focus on teachers' feeling of ambiguity toward their role. Especially with the changes in the educational movement in the Arab world and the change in teachers' social position. The social significance of the teacher's role and his place in society may be the most significant block of predictors of burnout, because, as this study shows, there is no correlation between occupational burnout and teaching performance. Thus, teachers have become unable to achieve their goals within the available methods. The same result was expressed by Abu Masoud (2010), who showed that administrative employees, working in the Ministry of Education in Gaza, suffered from a medium level of occupational burnout in general. While Altalla' (2015) showed a medium degree of occupational burnout in employees of Gaza electricity distribution company.

One of the most important specific reasons for burnout, researchers say, is the teacher's extrarole functions (Rehman, S.u., et al., 2017). Extra-role performance behaviors or what is called organizational citizenship behaviors might impact teaching effectiveness as well, e.g. cause psychological burnout. The teacher, who has a day full of work, stress, demands, and problems to deal with, will suffer from frequent and severe psychological burnout, which will affect in future his/her teaching performance. This result agrees with Anthony-McMann et al. (2017), who showed that job stress led the employees to occupational burnout and they became unable to achieve perfect results.

\section{Conclusion}

The study was conducted during 2018-2019 on the sample consisted of 60 Arabic language teachers (28 female and 32 male) from Al Ain University. There are significant statistical differences at the level $(a=0.05)$ in the sample responses about the level of occupational burnout among AAU teachers ascribed to the gender variable $(F=5.64)$, which is statistically significant, in favor of females. While the mean of 3.29 in table 3 shows that the differences are. The researchers ascribe this result to increased workloads and stress that female teachers face. This result can be justified by saying that female teachers are more exposed to occupational burnout than male teachers because female teachers also face loads on a personal level such as home routines, child care, etc. Contrary to earlier studies, there are no significant statistical differences ascribed to qualification variable. This result ascribes to the fact that all teachers with different scientific qualifications face similar circumstances and stress, reduced the differences in the levels of their occupational burnout. There are no significant statistical differences about the level of occupational burnout among AAU teachers ascribed to experience variable, but $F$ value 

college of education (evaluation study), International Journal of Cognitive Research in Science, Engineering and Education (IJCRSEE), 8(3), 19-28.

is 14.81 , which is statistically significant. Scheffe test was applied additionally it and shows the differences between teaching experience " $5-10$ years" and "more than 10 years" in favor of the experience "more than 10 years" (with a mean of $F=3.40$ ). The researchers ascribe this result to the fact that teachers with long experience are comparably more exposed to burnout. The study emphasizes the need to provide teaching staff with specialized consultations and training for them to be able to cope with job stress and psychological burnout. It is also important to reduce workloads that increase vocational stress so that teachers can avoid occupational burnout. Further studies might focus on psychological burnout and its relation to job satisfaction among lecturers of Arab universities.

\section{Acknowledgments}

We would like to thank all those who have contributed to this text, i.e. the academic stuff and the authorities of Al Ain University.

\section{Conflict of interests}

The authors declare no conflict of interest.

\section{References}

Abu Masoud, S. (2010). Occupational burnout phenomenon among management employees working within the ministry of education in Gaza strip - its causes and how to cure it. MA thesis, Islamic University. Gaza.

Abu-Hilal, M., \& Kilani, H. (2018). Structure of Burnout among Omani Male and Female Teachers: Invariance of Structure across Gender. Journal of Educational and Psychological Studies [JEPS], 12(4), 739-749. http://dx.doi.org/10.24200/ jeps.vol12iss4pp739-749

Al Serhan, O. (2020). Academic capitalism and faculty burnout: evidence from the United Arab Emirates. Cypriot Journal of Educational Sciences, 15(5), 1249-1274. https://doi.org/10.18844/cjes.v15i5.5176

Alfarra, I. (2004). Evaluating verbal summer-teaching performance for basic stage teachers. Proceedings of the Quality in Teaching Conference, University of Palestine. Gaza.

Alnouri, M. (2011). Measuring the dimensions of psychological burnout and its relationship to the demographic changes for the teaching committee in some colleges and institutes in Baghdad. Journal of Management and Economic, 86, 85-99.

Altalla', S. (2015). The fact of occupational burnout and its causes among the workers of Gaza Governorate Electricity Distribution Company. Alazhar University Journal, Human Science Series, 1(2), 181-214.

AnthonylMcMann, P. E., Ellinger, A. D., Astakhova, M., \& Halbesleben, J. R. (2017). Exploring different operationalizations of employee engagement and their relationships with workplace stress and burnout. Human Resource Development Quarterly, 28(2), 163-195. https://doi.org/10.1002/hrdq.21276

Atiyat, O. K. (2017). The Level of Psychological Burnout at the Teachers of Students with Autism Disorders in Light of a Number of Variables in Al-Riyadh Area. Journal of Education and Learning, 6(4), 159-174. http://doi.org/10.5539/jel.v6n4p159

Bal-Taştan, S., Davoudi, S. M. M., Masalimova, A. R., Bersanov, A. S., Kurbanov, R. A., Boiarchuk, A. V., \& Pavlushin, A. A. (2018). The impacts of teacher's efficacy and motivation on student's academic achievement in science education among secondary and high school students. EURASIA Journal of Mathematics, Science and Technology Education, 14(6), 2353-2366. https://doi.org/10.29333/eimste/89579

Bawakid, K., Abdulrashid, O., Mandoura, N., Shah, H. B. U., Ibrahim, A., Akkad, N. M., \& Mufti, F. (2017). Burnout of physicians working in primary health care centers under Ministry of Health Jeddah, Saudi Arabia. Cureus, 9(11). https://doi. org/10.7759/cureus. 1877

Davis, M. (2017). Teaching design: A guide to curriculum and pedagogy for college design faculty and teachers who use design in their classrooms. Simon and Schuster. Retrieved from https://idoc.pub/documents/teaching-design-aguide-to-curriculum-and-pedagogy-for-college-design-faculty-and-teachers-who-use-design-in-their-classroomsd4p7qv0mg94p

Garcia-Arroyo, J. A., Osca Segovia, A., \& Peiró, J. M. (2019). Meta-analytical review of teacher burnout across 36 societies: the role of national learning assessments and gender egalitarianism. Psychology \& Health, 34(6), 733-753. https://doi. org/10.1080/08870446.2019.1568013

Harzallah, H. (2018). Palestinian Teachers' Views on the Factors That Limit Students' Creativity and Some Possible Strategies to Overcome Them. Research In Social Sciences And Technology, 3(2), 40-57. Retrieved from https://www.learntechlib. org/p/187522/

Kim, L. E., Jörg, V. \& Klassen, R. M. (2019). A meta-analysis of the effects of teacher personality on teacher effectiveness and burnout. Educational Psychology Review 31, 163-195 https://doi.org/10.1007/s10648-018-9458-2

Lastovkova, A., Carder, M., Rasmussen, H. M., Sjoberg, L., de GROENE, G. J., Sauni, R., ... \& Varga, M. (2018). Burnout syndrome as an occupational disease in the European Union: an exploratory study. Industrial health, 56(2), 160-165. https://www.jstage.jst.go.jp/article/indhealth/56/2/56_2017-0132/_pdf

Nuri, C., Demirok, M. S., \& Direktör, C. (2017). Determination of self-efficacy and burnout state of teachers working in the special education field in terms of different variables. Journal of Education and Training Studies, 5(3), 160-166. https:// doi.org/10.11114/jets.v5i3.2237

Rehman, S.u., Qingren, C., Latif, Y. \& Iqbal, P. (2017). Impact of psychological capital on occupational burnout and performance of faculty members, International Journal of Educational Management, 31(4), 455-469. https://doi.org/10.1108//JEM- 
Alwaely, S. A., \& Jarrah, H. Y. (2020). Occupational burnout and its relation to academic staff performance at Al Ain University, college of education (evaluation study), International Journal of Cognitive Research in Science, Engineering and Education (IJCRSEE), 8(3), 19-28.

\section{1-2016-0011}

Torkaman, F., Farhang, S., Zakerian, S. A., Torkaman, M., \& Niaragh, H. K. (2017). A study on the effect of job burnout and stress on job satisfaction among teachers of exceptional schools. Pharmacophore, 8(5), 18-24. Retrieved from https:// pharmacophorejournal.com/storage/models/article/vNQjkPAuCJFOSdeRZEoVt9HYIrsRoQtmZkxgnPAOUncw68Mml JqLK3azxP9p/a-study-on-the-effect-of-job-burnout-and-stress-on-job-satisfaction-among-teachers-of-exceptional-.pdf

Ward, P., \& Ayvazo, S. (2016). Pedagogical content knowledge: Conceptions and findings in physical education. Journal of Teaching in Physical Education, 35(3), 194-207. https://doi.org/10.1123/jtpe.2016-0037

Woodhead, E. L., Northrop, L., \& Edelstein, B. (2016). Stress, social support, and burnout among long-term care nursing staff. Journal of applied gerontology, 35(1), 84-105. https://doi.org/10.1177/0733464814542465

Yorulmaz, Y. I., \& Altinkurt, Y. (2018). The examination of teacher burnout in Turkey: A meta-analysis. Turkish Journal of Education, 7(1), 34-54. https://doi.org/10.19128/turje.348273 